\title{
La anexión de México a los Estados Unidos según Matías Romero, 1888
}

Enrique Arriola Woog.

Después de la firma del Tratado de Guadalupe Hidalgo (1848) que ponía fin a la invasión, el tema de una posible anexión del norte de México a Estados Unidos ocupó, en un plano relevante, la atención de la prensa de ese país.

Cuatro décadas más tarde, el asunto seguia causando polémica. La insistencia de ciertos diarios estadunidenses al respecto causó inquietud y preocupación en los círculos oficiales de México. Según los periódicos allende el río Bravo, tanto liberales como conservadores reflexionaron acerca de una eventual expansión del destino manifiesto.

Empero, la actitud para enfrentar el asedio era muy distinta en su naturaleza y sentido: unos estimaban que el medio idóneo para contener el acoso consistía en permitir la entrada al capital foráneo; otros abogaban por una estrategia de retraimiento frente a la amenaza de los herederos de la Doctrina Monroe.

En el transcurso de octubre de 1888, el Herald de Boston y el Post de Washington publicaron sendos artículos, cargados de ironía, referentes a los temores que tal política de fuerza generaba en el régimen del general Porfirio Díaz. Entonces el quinto poder convergia en sus propósitos con los lineamientos del Departamento de Estado. Así, los síntomas de desconfianza e inseguridad no eran del todo gratuitos.

A manera de corroboración, el mismo ministro de México en Washington, Matias Romero, opinaba que el espíritu expansionista estaba tan hondamente arraigado en la conciencia colectiva norteamericana que, si el asunto fuese sometido a votación popular directa, la mayoría de las clases y los sectores sociales aprobarían el proyecto.

El debate se transformó en problema nacional y alrededor de la anexión sesionó el Congreso. En noviembre, el senador republicano John J. Ingalls afirmó en un discurso: "tanto el Canadá como México, Cuba, las Indias Occidentales y de hecho todo el continente americano deberían de anexarse a la Unión". Para esa época sólo los miembros del Partido Demócrata sostenían ideas e intenciones semejantes, situación que expresa un enorme peligro, un indicador de mayor verosimilitud de la empresa de conquista y ampliación del territorio estadunidense.

Por si fuera poco, los habitantes del sur de California sometieron a la aprobación del poder legislativo federal una propuesta de dividir el estado: la ciudad de Los Angeles fungiría de capital de la parte meridional $y$, para que esa estrella del norte no resultase muy pequeña, pretendian adquirir, previo pago, la Baja California. De tal suerte controlarían toda la península y dicha extensión bien ameritaba constituir dos estados. 
La pretensión de marras cobró notoriedad pública, por encima del carácter patrimonial de la Razón de Estado norteamericana, cuando en diciembre un editorial de la Unión de San Diego señaló que la compra del territorio se realizaría con el consentimiento del gobierno de México. ¿Cuál era su argumento? Ni más ni menos que el costo real de la península no excedia la oferta de 15 millones de dólares.

Seguramente, los ciudadanos de la metrópoli, del imperio creciente, consideraban que con la operación le hacian un favor a su vecino del sur. Para el común de los californianos, la adquisición de la Baja California sólo significaba la incorporación de un pedazo de tierra ligado a su amor propio. Sin embargo, la administración del entonces presidente de los Estados Unidos, Robert Cleveland, le confería un gran valor estratégico. ${ }^{1}$

Ante la campaña en favor de la anexión promovida por la prensa yanqui, Matías Romero recibió instrucciones claras y precisas de la Cancilleria mexicana: ofrecer una conferencia a los representantes de los periódicos de mayor influencia de la Unión Americana 0 , en su caso, publicar un artículo relativo a los inconvenientes que tendria la pretendida anexión para ambos Estados.

El ministro de la Legación de México en Washington se abocó de inmediato a la tarea; elaboró un documento con la intención requerida por el secretario de Relaciones Exteriores, Ignacio Mariscal. En una nota del 21 de diciembre de 1888 le informó que había discutido el trasfondo del affaire con diferentes personalidades intelectuales y politicas norteamericanas, y que a raíz del intercambio de opiniones su escrito sufrió modificaciones de consideración.

De las conversaciones que sostuvo destaca la efectuada con el senador Morgan. Este personaje le sugirió que pensase en la pertinencia de publicar el material en un periódico de cobertura nacional, más que en conceder alguna entrevista para los diarios neoyorkinos. Asimismo, el agente diplomático mexicano quiso ahorrarle contratiempos al secretario de Estado saliente, Thomas Francis Bayard, conocido por su oposición al expansionismo, por lo que le remitió una copia del artículo de referencia.

Matías Romero no perseguía la aprobación del funcionario estadunidense, ya que la posición de éste frente a la política de expansión era del dominio de la opinión pública. En contra de la mayoría de sus compatriotas se opuso al tratado celebrado con Nicaragua sobre la apertura de un canal interoceánico, dados los inconvenientes de seguridad y protección que presenta el proyecto.

\footnotetext{
' Años después, en mayo de 1923, en el marco de la Conferencia de Bucareli, el almirante retirado William $S$. Sims le dirige una carta al secretario de Guerra, John W. Weeks, donde se consigna el carácter logistico-militar de la peninsula: “...la bahia de Magdalena en la costa de Baja California, la cual dada la importancia estratégica que presenta al enemigo es de todo punto indispensable que se haga posible porque quede bajo nuestro control, ya que México, de grado o por la fuerza que le imponen los tratados que tiene con nosotros, prácticamente nos concede el control en determinadas circunstancias, pues si mal no recuerdo es el espíritu de ciertos artículos de nuestros tratados con México desde 1848 y 1853 ". Véase AGNM, fondo Secretaria de la Presidencia, Obregón/Calles, Exp. 104-A-23.
} 
De los rotativos norteamericanos que se interesaron-más por la publicación del artículo, sobresalió el North American Review. Este diario se comprometió a darlo a la luz en febrero de 1889 , si se entregaba el material antes de que concluyera el año de 1888 . Sin embargo, su aparición se retrasó hasta mayo, debido con seguridad a que la Cancillería mexicana consideró más oportuno hacerlo con posterioridad a la toma de posesión del nuevo presidente de Estados Unidos, Benjamin Harrison.

La versión española se dio a conocer en Las Novedades de Nueva York, el 20 de mayo de 1889. Sin duda, desde aquella época, la política exterior de México ha buscado difundir sus posiciones, principios y actitudes. El memorándum preparado por Matías Romero respondió al título de "La anexión de México a los Estados Unidos".

A casi cien años de distancia, los argumentos de Matias Romero adquieren su pleno sentido: la defensa del interés nacional. Tarea ésta igualmente compleja en el presente que en aquel ya lejano año de 1888 . Hoy, las presiones en contra de la soberanía de México son distintas. Empero, la continuidad de la politica exterior renueva lo mejor de su tradición y encarga los embates foráneos con la misma entereza y dignidad.

Washington, diciembre 31 de 1888

\section{INCONVENIENTES DE LA ANEXIÓN DE MÉXICO A LOS ESTADOS UNIDOS*}

Haciéndose con frecuencia alusiones en la prensa de esta nación y aun por algunos de sus hombres públicos, a la anexión de México a los Estados Unidos y temiendo que aquellos de nuestros conciudadanos que no están bien informados de la situación que actualmente guarda este pais y de las serias dificultades que esa empresa ocasionaría, si se tratara de realizarla, me ha parecido oportuno hacer una ligera enumeración de esas dificultades, con objeto de calmar los temores que se puedan abrigar a este respecto y de demostrar los serios inconvenientes y casi imposibilidad que habria de llevar a cabo la anexión de México.

Al tratar este asunto en la presente nota, me limitaré a estudiar la cuestión bajo el punto de vista del interés de los Estados Unidos, porque siendo unánime en México la repugnancia a la anexión es excusado estudiarla bajo el punto de vista en que podría considerarla un mexicano.

Me parece oportuna la discusión de este asunto porque las cuestiones de carácter trascendental deben estudiarse cuando no están pendientes de resolución, y cuando, por lo mismo, la opinión pública no está preocupada respecto de ellas y es accesible a la razón. En este caso se encuentra actualmente la cuestión que apenas puede llamarse tal, de la anexión de México a los Estados Unidos.

Ninguno de los partidos políticos de este país, y en verdad ningún hombre sensato de él favorece ahora ese proyecto, en caso de que se intentara llevarlo a cabo por la fuerza, y creo que muy pocos lo acep-

* El texto preparado por el ministro mexicano se encuentra en el Archivo Historico "Genaro Estrada" de la Secretaría de Relaciones Exteriores (AREM) en la correspondencia encuadernada de la serie "Embajada de México en los Estados Unidos de América" (EMEUA), vol. 376, núm. 1405. La ortografia del documento ha sido actualizada para facilitar la lectura. 
tarian aun en caso de que la anexión fuera solicitada espontáneamente por México, si llegasen a pesar sus serias consecuencias. Solamente las' personas interesadas en obtener puestos prominentes en los nuevos Estados, o aventureros ansiosos de trastornos para utilizarlos en su propio engrandecimiento, o unos cuantos especuladores, con esperanza de hacer contratos lucrativos, en caso de guerra, favorecerían la anexión a toda costa.

No creo que deba darse mucha importancia a las opiniones expresadas aquí sobre este asunto. La libertad de la palabra tanto impresa, como hablada por los hombres públicos de este país, es tan amplia que su propia extravagancia le sirve de correctivo, y nadie toma a lo serio las exageraciones de la prensa o de la retórica política, sino en el caso de que exprese la opinión oficial de funcionarios colocados en alta posición, que hablen en su carácter oficial y con la responsabilidad consiguiente a él.

Puedo asegurar a Ud. por el conocimiento que tengo de este país y mis relaciones con sus hombres públicos, lo mismo que por su estudio especial que he hecho de la opinión pública a este respecto, que ninguno de los dos partidos que alternativamente han regido los destinos de esta nación y ningún número de personas que puedan considerarse de alguna importancia desean o esperan la anexión de México.

De dos maneras podría llevarse a cabo la anexión: por fuerza o conquista, o por un acto voluntario de nuestro país. Estoy seguro de que no hay ahora ningún partido político en los Estados Unidos que favorezca la conquista de México aunque es innato el deseo de todo pueblo de aumentar su poder y su área; este deseo es diferente de un espíritu de conquista, sin embargo de que algunas veces no se pueda lograr aquel fin, sino por medio de la conquista.

Cuando la cuestión de la esclavitud dividía a este país, y el Norte estaba en contra del Sur, y las inmensas posesiones del Oeste eran ocupadas por hombres del Norte, o antagonistas de la esclavitud, natural era que el Sur buscara compensación, a costa de sus vecinos, porque esperaba que cada estado nuevo que viniese del Sur, sería un estado esclavo, o estado en que se estableciese la esclavitud. Este estado de cosas que hizo considerar entonces la adquisición de territorio al Sur casi como una medida de propia conservación, explica la causa y objeto de la guerra con México, y sus consecuencias, que fueron la adquisición de Texas, Nuevo México y California, lo mismo que los esfuerzos hechos entonces por administraciones democráticas de los Estados Unidos para comprar la isla de Cuba.

Pero aun en esto sufrió el Sur una terrible decepción, porque naturalmente esperaba que todo el territorio adquirido de México conforme al Tratado de Guadalupe Hidalgo, se convirtiera en estados esclavos, esto es que adoptasen la esclavitud, y de los cuatro estados en que se dividió aquel territorio, solamente uno, Texas, adoptó la esclavitud; y los otros tres, California, Nevada y parte de Colorado, se organizaron como estados libres, y de los tres territorios, Nuevo México, Utah y Arizona, en que se dividió el resto de aquella adquisición, tan sólo uno, Nuevo México, habria probablemente adoptado la esclavitud en caso de que hubiera sido organizado como estado antes de que se hubiera abolido la esclavitud. Si hubieran podido prever este resultado los promovedores de la guerra de México, es probable que no hubieran trabajado con tanto empeño en aquella empresa.

Así pues, el territorio adquirido de México, en vez de dar la preponderancia política en los Estados Unidos al partido que favorecía la esclavitud, que fue su único objeto y móvil, no hizo más que precipitar la lucha final para la abolición de la esclavitud, o la guerra de rebelión, como generalmente se le llama aquí, que tan desastrosa fue para el Sur.

Pero desde que se abolió la esclavitud en los Estados Unidos, el 
estado de cosas que antes prevalecía ha cambiado esencialmente, y la adquisición de territorio, cualesquiera que sean las razones que puedan alegarse en su favor, o la popularidad de esa idea, ha asumido una nueva faz, y muy seria por cierto, para este país, que afortunadamente no tiene ya nada que ver con la esclavitud.

Los Estados Unidos tienen ya más territorio del que haya tenido cualquiera otro pais libre, el cual abraza diferentes elementos con intereses distintos y antagonistas, que es probable que cada día se robustezcan más. Todo el patriotismo, el talento, la prudencia, la sabiduría y la integridad de sus mejores hombres de Estado tendrá que ponerse en juego, durante el siglo próximo, para mantener los lazos de unión que ahora afortunadamente existen, y para impedir la división de este pais, y en caso de que lleguen a obtener buen éxito en esa difícil tarea, habrán prestado un gran servicio a su patria.

El Imperio Romano, que es el gobierno que ha tenido mayor área de territorio, y el más estable de que hay noticia, exceptuando acaso el de China, no era un gobierno libre y popular como el que se ha establecido aquí, sino que, desde el tiempo de Augusto, fue un despotismo militar, aunque teniendo en cuenta la época, era ilustrado y tolerante con los pueblos que subyugaba; y sin embargo de esto, cuando se extendió mucho y abarcó elementos discordantes y antagónicos, se dividió, primero, entre el Imperio de Oriente y de Occidente, y finalmente, se desmoronó por completo.

Si los hombres de Estado de este país, cuyo deber es conducir esta gran nación a un puerto seguro, intentan aumentar las dificultades que ya existen y que es probable aumenten cada día más, incorporándole un pueblo de doce millones casi imposible de asimilar, a lo menos por muchas generaciones venideras, de diferente raza, que habla diferente lengua, que tiene diferentes costumbres e ideas, y de los cuales casi dos terceras partes son de indios de raza pura, que aunque dóciles, pacíficos y obedientes a la ley, están por lo general sin educarse y probablemente presentarían los mismos problemas sociales, económicos y políticos que ofrece la raza de color en el Sur, y que son tan dificiles de una solución satisfactoria, que muchos de los hombres más ilustrados de este país preferirian que desapareciera de él, la tarea de conservar unida esta gran nación, sería casi imposible de lograr.

Pero hay en mi concepto otra objeción, de más fuerza todavia, y de un efecto más inmediato. Los Estados Unidos están ahora casi igualmente divididos en política, entre el Norte y el Sur, de tal manera que un solo estado ha decidido con frecuencia reelecciones presidenciales. Desde la abolición de la esclavitud, que por varios años fue el punto de disidencia entre los partidos políticos, está tomando su lugar la cuestión social entre el capital y el trabajo, que más propiamente podría llamarse cuestión económica. Todo el Sur, o el Sur sólido, como se le llama aquí, se ha alistado de un lado, y la mayoría del Norte del otro. Si en tales circunstancias, y aun en el caso de que se llegara a un arreglo en esa o en otras cuestiones, se agregara a las dificultades de la situación presente, la de 12000000 de un pueblo heterogéneo, disgustado y forzado, el cual tendría una representación en el Congreso de los Estados Unidos de 56 senadores y 49 diputados, conforme a la distribución que está en vigor actualmente, con el número correspondiente de votos en el Colegio electoral, el porvenir y la suerte de este país se pondrían en manos de ese elemento disgustado, que ejercería entonces una influencia decisiva en sus destinos. Esa influencia aumentaria en proporción que aumentase el número de partidos políticos en este país.

No creo posible, a no ser que cambiasen radicalmente las instituciones politicas de esta nación, con objeto de atender a esta emergencia, que se excluyese a la población mexicana de los derechos politicos, 
especialmente cuando a la raza negra del Sur se ha concedido el derecho de votar y la misma representación en el Congreso de que disfruta la raza blanca.

Es cierto que los senadores y diputados mexicanos no podrían por sí solos, aprobar ninguna medida que tuviese la oposición de los demás; pero este hecho no los privaria de tener una influencia decisiva en el Poder Législativo de los Estados Unidos, y su número bastaría para que pudieran impedir la aprobación de muchas. Si en tales circunstancias se hubiese presentado la cuestión que se decidió en 1861 , y como es probable aquéllos se hubieran puesto del lado del Sur, la división de este pais habria tenido entonces la sanción del Poder Legislativo. Además, un número tan considerable de diputados y senadores, unidos y compactos, podrian obtener por transacción y otros arreglos usuales aquí, muchas ventajas en el curso de los negocios legislativos.

Si alguna vez asumieran los Estados Unidos el carácter de conquistadores, tendrian que hacer cambios esenciales en sus instituciones. La conquista y consiguiente opresión de un pueblo son contrarios a los principios proclamados en la declaración de Independencia de este país, incorporados después en la Constitución de los Estados Unidos, en virtud de los cuales se ha establecido aquí un Gobierno del pueblo y para el pueblo.

Si los Estados Unidos llegaran a adquirir la solidaridad de unión política que funde al individuo en la nación, como ha pasado en algunas potencias, en las que la soberanía nacional tiene todos los atributos de una personalidad, mientras que la significación individual se pierde, el cambio de instituciones podría, tal vez, tener lugar; pero ahora la unidad de la soberania es el individuo, representada por las mayorias. México, por el contrario, es una nación tan compacta como cualquiera otra, y los diferentes cambios de Gobierno que ha experimentado, no han afectado para nada su nacionalidad.

Si los Estados Unidos intentasen seguir la política de anexión, sería natural que comenzasen con el Canadá, puesto que los canadienses pertenecen a la misma raza, tienen el mismo origen y costumbres, hablan la misma lengua, profesan la misma religión y son, prácticamente, el mismo pueblo dividido tan sólo por una línea imaginaria; y sin embargo, no hay aquí, que yo sepa, ningún partido que favorezca la unión del Canadá por la fuerza o conquista, y aun algunos de los hombres más prominentes de este país han expresado decidida oposición a aquella medida, aun en el caso de que ella fuere solicitada por el voto espontáneo de los canadienses. Una de las razones que con más fuerza se alegan en contra de esa unión es que cosa de unos cuantos de los canadienses son de origen francés y por lo mismo de difícil asimilación.

Hay otro hecho que demuestra cuán difícil es de llevarse a cabo la consolidación de gobiernos, o la anexión, con las instituciones que prevalecen en este país. Grandes esfuerzos se han hecho de algún tiempo atrás para consolidar en un solo Gobierno municipal las dos ciudades gemelas, Nueva York y Brooklyn. Ambas son realmente una sola ciudad dividida tan sólo por un río, comunicadas ya por un puente, como lo están Londres por el Támesis, París por el Sena y Roma por el Tíber; y sin embargo, esa consolidación no ha podido efectuarse, y mucho tiempo tendrá que transcurrir antes de que se lleve a cabo. ¡Cuánto más difícil no será la consolidación en un solo Gobierno de dos naciones diferentes!

Si este país hubiera tenido el propósito de anexarse una parte del territorio mexicano, la ocasión más oportuna de verificarlo habría sido sin duda la que presentó la intervención francesa en México. Terminada la guerra civil en los Estados Unidos en mayo de 1865, quedó el país con un ejército disciplinado y de veteranos de más de medio mi- 
llón de soldados, y pudo muy bien haber consagrado una parte de él a auxiliar materialmente a México en su guerra contra el emperador de los franceses, exigiendo al terminarse ésta, a pesar de la resistencia de México, el pago, en territorio, de los gastos que la guerra hubiera ocasionado. Lejos de seguir esa política, la Administración que entonces regía los destinos de este país prefirió seguir una conducta neutral, precisamente para evitar la posibilidad de aquel resultado. En aquella época era yo el representante de México en Washington, y conozco bien por lo mismo las miras de aquella administración. La desaprobación del tratado de anexión de Santo Domingo es otro hecho muy significativo.

Intencionalmente me he abstenido de tomar en cuenta las graves dificultades que presentaria la subyugación de 12000000 de un pueblo valiente, orgulloso de su nacionalidad y dispuesto a luchar por ella hasta el último extremo, y de las dificultades de conservar subyugada a tanta gente; porque estas consideraciones, aunque graves de por si y que en concepto de muchas personas serían bastantes para no acometer la empresa, y en ningún caso deberian perderse de vista, tienen una importancia secundaria cuando se comparan con la trascendental importancia de las otras; y he querido dar por concedido que la conquista de México pudiera efectuarse. Pero es oportuno recordar que una grande autoridad militar dijo hace poco que una guerra con México sería cosa muy diferente de la que tuvo lugar en 1846 y 1847 y que sus consecuencias serian igualmente diferentes. Aunque es una ley de la naturaleza que el más fuerte prevalezca sobre el más débil, hay ciertos factores en la lucha entre dos naciones que pueden afectar seriamente sus consecuencias, y los esfuerzos que tengan que hacerse pueden ser de tal magnitud, que no compensen con sus resultados.

Cuando se tiene en cuenta que el espíritu de la época es extender, más bien que restringir el gobierno autónomo (Self Government), y que las naciones principales del mundo, las que han hecho las conquistas más grandes, han llegado a reconocer que el mejor modo de conservar sus dependencias o colonias es concederles la ventaja preciosa de la autonomia -principio practicado aquí en mayor escala que en cualquiera otra parte, y que explica en gran manera la conservación, progreso y crecimiento de este gran país-, parecería casi una locura supoiner que fuera negada a México, en caso de su anexión a los Estados Unidos, aun cuando ésta pudiera verificarse por medio de conquista.

Los Estados Unidos repulsan ahora decididamente la inmigración de chinos, por la razón principal de que trabajan por salarios más bajos que los naturales del país. La tendencia de impedir la competencia de los trabajadores que ganan jornales bajos, con los trabajadores del país, crece cada día más, y ha empezado ya a incorporarse en las leyes relativas a inmigrantes extranjeros, existiendo una marcada tendencia para restringir lo que se llama inmigración del pauperismo.

La anexión de México revolucionaría por completo el sistema de trabajo en los Estados Unidos, aumentando diez veces más las objeciones que presenta la inmigración de chinos y de europeos desvalidos, 3000000 por lo menos, de trabajadores mexicanos, cuyos salarios son actualmente de $121 / 2$ a 50 centavos al día, y que estarían dispuestos a venir al norte $o$ al oeste de este país, para ganar jornales más altos, se presentarian en el mercado, revestidos con el derecho de ciudadanos y sin la posibilidad de que se les cerraran las puertas de este pais, como ahora se han cerrado de hecho a los chinos. Es seguro que entonces se les tendría que pagar más de lo que ahora ganan en México; pero en todo caso sus salarios serían menores que los que actualmente se pagan a los chinos.

La política más sabia que puede seguirse entre México y los Estados Unidos, y a la cual parece que profesan ahora todos los partidos po- 
líticos de este país, debería ser, en mi opinión, la de establecer relaciones políticas, comerciales y sociales entre las dos Repúblicas, de tal naturaleza que las identifiquen en grandes intereses comerciales e industriales; pero sin disminuir la autonomía o nacionalidad de ninguna de ellas. Esa política daría a los Estados Unidos y a México todas las ventajas de la anexión, sin ninguno de sus inconvenientes. Ambos países han hecho ya prácticamente de su territorio un solo territorio postal. Es de esperarse que mucho antes de sus relaciones comerciales hayan crecido en tales proporciones que sea posible y conveniente para ambos algo más que la reciprocidad comercial. La contigüidad territorial, y la estrecha unión por varias líneas troncales de ferrocarril, precipitará necesariamente este resultado.

La opinión pública en México ha estado dividida respecto de la política que debe seguirse con relación a los Estados Unidos. El partido conservador, lo mismo que una gran parte del pueblo mexicano, inspirados por el recuerdo de la guerra desastrosa de 1846 y 1847 que el general Grant caracterizó de injusta, y sin apreciar debidamente los cambios políticos que desde entonces han tenido lugar en este país, está siempre temeroso de la anexión y aconseja el sistema de aislamiento y completa incomunicación con los Estados Unidos, mientras que el partido liberal, que tiene el vínculo de semejanza de instituciones políticas, considera que la contigüidad de territorio es un hecho inevitable, que no se puede ignorar, y cree que la mejor manera de impedir la anexión es abrir el país a los Estados Unidos y concederles todas las franquicias razonables con objeto de hacer la anexión innecesaria y hasta peligrosa. Siguiendo esta política, las leyes antiguas de México sobre terrenos baldios han sido modificadas recientemente y se han hecho a los ciudadanos de este país concesiones muy liberales en materia de ferrocarriles, de minas y de todo género.

Pero ambos partidos, y en verdad el país entero, como un solo hombre, está decididamente opuesto a la anexión, no sólo porque está orgulloso de su nacionalidad, sino también porque tiene la convicción de que la anexión significaria para ellos el exterminio y, naturalmente, no están dispuestos a su propia destrucción. No participo yo de estos temores, por lo que hace el exterminio de la raza que actualmente ocupa México, porque no creo que 12000000 de habitantes puedan ser fácilmente exterminados; pero esto no cambia la situación, cuando el país entero lo considera asi.

Creo que estas ligeras observaciones son suficientes para decidir de la cuestión de anexión por la voluntad espontánea de los mexicanos.

Por ahora y probablemente por algún tiempo más, la reciprocidad comercial es todo lo que se necesita para desarrollar las relaciones mercantiles entre los dos países. La contigüidad territorial y las bandas de acero que los unen ahora, requieren reglas especiales para regir y aumentar su comercio, algún tanto diferentes de las que se aplican a los demás países. La reciprocidad tiene, además, la ventaja de que permite que se reformen las leyes de importación de un país, con una compensación equivalente y a la vez con beneficio para el otro pais. $\mathrm{Si}$, por ejemplo, los Estados Unidos desearen, ahora, con objeto de reducir sus ingresos o por alguna otra razón, abolir los derechos sobre el azúcar, como hace poco abolieron los derechos sobre el café, no ganarian más resultado, si la abolición se.hiciera general para todos los paises, que el de disminuir sus rentas. Pero si los abolieran tan sólo para México, recibirian una compensación equivalente en favor de sus productos y manufacturas.

La reciprocidad, tal como se convino con México, en el tratado pendiente, tiene también la ventaja de que no restringe en manera alguna la facultad constitucional del Congreso de cada país para alterar sus respectivas leyes fiscales. 
La unión comercial presenta muchas mayores dificultades. Si por unión comercial entre dos países se entiende que ambos tengan las mismas tarifas, o leyes, para la importación de mercancías extranjeras y que reciban libres de derechos las mercancías del otro país, se presenta desde luego la dificultad de quién formará, modificará y derogará tales leyes. Si ha de ser ésta facultad de los Congresos de cada país obrando simultánea pero independientemente, sería muy difícil que pudieran llegar a un acuerdo, representando naciones con diferentes necesidades e intereses. Un Congreso común, en que ambos países estuvieran representados, tendría inconvenientes muy serios, además de que para establecerlo se requeriría la modificación de las Leyes fundamentales de los dos. Ambos tendrían que estar representados en él, o como iguales, o en proporción a su población o territorio. Si como iguales, el más grande sufriría en sus intereses; y si en proporción a su población o territorio, el más pequeño sería la víctima.

Pero aun restringiendo la unión comercial a la importación, libre de derechos en ambos países, de los productos y manufacturas del otro -cuya medida podría llamarse más propiamente reciprocidad absoluta o sin restricción-, teniendo cada uno el derecho de expedir sus respectivos aranceles, de acuerdo con las prescripciones de sus Leyes funda. mentales, por lo que hace a los derechos de importación para los productos y manufacturas de otros países, debería convenirse en la manera de modificar dichos aranceles, porque en el caso, por ejemplo, de que las manufacturas de algodón de todos los paises se declarasen libres a su importación en México, los Estados Unidos dejarían entonces de obtener las ventajas de la reciprocidad; y la manera de modificar dichos aranceles es un asunto muy difícil de decidir, porque tendría que darse a cada país alguna injerencia en la formación de las leyes del otro, que probablemente no sería aceptable para ninguno de los dos y que requeriría, también, en ambos, la modificación de sus Leyes fundamentales.

Así, pues, el asunto de la unión comercial con México presenta problemas tan complejos, que es más conveniente dejar que las necesidades y exigencias del porvenir indiquen la manera de resolverlos, y por ahora todos los intereses y necesidades de ambos países quedarian, en mi opinión, satisfechos, con una reciprocidad restringida como la que se convino en el tratado pendiente.

Para concluir, creo conveniente expresar mi opinión de que los Estados Unidos desean ante todo la estabilidad y prosperidad de México y de las demás naciones hispanoamericanas, y quieren sinceramente estrechar sus relaciones amistosas con ellas. Es un hecho que hasta ahora no nos conocemos los unos a los otros, y el conocimiento recíproco es el primer paso para llegar al resultado más satisfactorio.

Mucho celebraré que la reunión en esta ciudad en el mes de octubre del año próximo, de una asamblea de representantes de las naciones americanas, pueda contribuir al resultado de despertar el interés en todas ellas de conocerse recíprocamente.

Reitero a Usted mi muy distinguida consideración.

M. Romero

Al Secretario de Relaciones Exteriores México 